\title{
La formación del profesional desde el enfoque de género en el Derecho Penal cubano
}

\section{The training of professionals from the gender perspective in Cuban Criminal Law}

\section{Jorge Luis Silva-González}

Licenciado en Derecho.

Profesor principal de Derecho Internacional Público.

Jefe de la Disciplina de Derecho Internacional del

departamento de Derecho de la Universidad

Hermanos Saíz Montes de Oca de Pinar del Río, Cuba.

Contacto: $\underline{\text { silva@upr.edu.cu }}$

\section{Alie Pérez-Véliz}

Licenciado en Derecho.

Doctor en Ciencias Pedagógicas.

Profesor Titular de Teoría del Estado y el Derecho.

Jefe del departamento de Derecho de la

Universidad Hermanos Saíz Montes de Oca de Pinar del Río, Cuba.

Contacto: alievez@upr.edu.cu

\section{Lisett D. Páez-Cuba}

Licenciada en Derecho.

Doctora en Ciencias Pedagógicas.

Profesora de Derecho Penal Especial del departamento

de Derecho de la Universidad Hermanos

Saíz Montes de Oca de Pinar del Río, Cuba.

Contacto:lisett@upr.edu.cu. 


\title{
Resumen
}

El presente artículo tiene como objetivo contribuir a la formación del profesional del Derecho en Cuba, a partir del análisis del enfoque de género en el Derecho Penal, desde la perspectiva de la equidad, específicamente en los delitos de Violación, Pederastia con Violencia y Abusos Lascivos, correspondientes a los delitos contra el normal desarrollo de las relaciones sexuales del Código Penal. Se caracteriza el proceso formativo del jurista en las universidades cubanas, se hace referencia a la teoría del enfoque de género y la equidad, así como una comparación jurídica a la regulación del delito de violación en España, Argentina, Bolivia, Venezuela, Costa Rica, Ecuador, Colombia, Italia y Alemania. Dentro de los resultados se obtuvo, que el enfoque de género en el Derecho Penal cubano tiene carácter tradicionalista, sexista y biologicista, al ofrecer mayor importancia a la integridad sexual del hombre que a la de la mujer.

\section{Palabras clave}

Géner, formación, equidad, Derecho Penal, delito de violación.

\begin{abstract}
This article aims to contribute to the training of legal professionals in Cuba, based on the analysis of the gender approach in Criminal Law, from the perspective of equity, specifically in the crimes of Rape, Pederastia with Violence and Lascivos Abuses, Corresponding to crimes against the normal development of sexual relations of the Penal Code. It is characterized the jurist's formative process in Cuban universities, reference is made to the theory of the gender approach and equity, as well as a legal comparison to the regulation of rape in Espain, Argentina, Bolivia, Venezuela, Costa Rica, Ecuador, Italia and Germany. The results showed that the gender approach in Cuban criminal law has a traditionalist, sexist and biologicist character, since it gives greater importance to the sexual integrity of the man than to that of the woman.
\end{abstract}

\section{Keywords}

Gender, training, equity, Criminal Law, crime of rape. 


\section{INTRODUCCIÓN}

En la actualidad, el tratamiento de la temática de género continúa siendo un imperativo para las Universidades cubanas, en aras de contribuir desde la graduación de profesionales a una sociedad más justa y equitativa. Las Ciencias Sociales muestran avances teóricos significativos en este sentido, mas el reto de implementar los propios resultados aún dista de la voluntad y el esfuerzo de los cientistas, que no intervienen solos en el proceso por lograr que mujeres y hombres gocen de igualdad de derechos y oportunidades (Silva \& Pérez, 2017).

La Ciencia Jurídica específicamente, presenta un despertar y se anima por hacer prevalecer el principio de igualdad plasmado en la Constitución de la República de Cuba de 1976 y que se evidencia en el artículo 41 en relación con el 43, del Capítulo VI "Igualdad", a que todos los ciudadanos gozan de iguales derechos y están sujetos a iguales deberes, asimismo, que la mujer y el hombre gozan de iguales derechos en lo económico, político, cultural, social y familiar.

$\mathrm{Si}$ bien los artículos expuestos anteriormente en la Constitución, claramente evidencian la regla general de que en una sociedad socialista ambos sexos tienen igualdad ante la ley, algunas normas del ordenamiento jurídico son tendentes a reproducir patrones discriminatorios, que en ocasiones ubican en posición de desventaja a las mujeres al sustentarse en políticas igualitarias, mientras que en otras, se conciben tratamientos diferenciados, cuando lo más conveniente sería una formulación única para ambos sexos.

El Derecho Penal cubano, sin absolutizar, contiene algunas de ellas, razón por la que el siguiente artículo tiene como objetivo: contribuir a la formación del profesional de Derecho en Cuba, a partir del análisis del enfoque de género en el Derecho Penal desde la perspectiva de la equidad, en los delitos de Violación-298.1, Pederastia con Violencia-299.1 y Abusos Lascivos-300.1, del Código Penal.

En el caso del delito de Violación, se compara jurídicamente en países del Sistema de Derecho Romano - Francés, tales como España, Argentina, Bolivia, Venezuela y Alemania, por poseer una regulación diferente a la cubana y ajustada a la perspectiva de la equidad.

En el artículo se particulariza además en la universidad como centro educativo, con énfasis en la triada género- Derecho Penal- equidad.

Esta investigación resulta actual y pertinente teniendo en cuenta las carencias existentes actualmente en el proceso de formación del profesional del Derecho en materia de género, y precisamente a través de la Didáctica, como ciencia que estudia el proceso de enseñanza-aprendizaje de carácter sistémico y eficiente en marcos curriculares, se analiza el comportamiento que tiene el enfoque de género en el Código Penal y su trascendencia en el currículo. 


\section{DESARROLLO}

\section{Consideraciones teóricas sobre la formación del profesional del Derecho en Cuba}

La formación de profesionales competentes es un anhelo internacional que se convierte en un reto fundamental para la Universidad cubana. La enseñanza del Derecho, en consonancia con las exigencias de la Educación Superior y con el reclamo de trasformación que la comunidad internacional demanda en materia de género, requiere ser perfeccionada. En tal sentido, el proceso de formación de juristas con perspectiva de género es un tema que amerita ser estudiado desde las Ciencias de la Educación, Jurídica y Sociológicas.

El vocablo proceso proviene del latín procesus, que significa paso, avance. Según el Diccionario Pequeño Larousse llustrado es la evolución de una serie de fenómenos. En el Diccionario Filosófico (Rosental, 1981, p. 376) se refiere a los fenómenos, acontecimientos, hechos que se suceden, pasando por diferentes estados. Se define como transformación sistemática, sujeta a la ley, de un fenómeno; como el paso del mismo a otro fenómeno: desarrollo (Silva, Páez \& Simón, 2016).

Para Álvarez (1999) un proceso es una sucesión de estados de un objeto determinado. Otros autores lo definen como una transformación sistemática de los fenómenos sometidos a una serie de cambios graduales, cuyas etapas se suceden en orden ascendente; como tal, solo puede entenderse en su desarrollo dinámico, su transformación y constante movimiento (Colectivo de Autores, 1984, p. 182).

Se entiende por proceso la sucesión de etapas de desarrollo de un fenómeno orientado hacia un fin determinado. De esta idea se colige que todo proceso debe tener los siguientes elementos: actor, actividad, etapas y misión. El actor es el agente, el sujeto que interacciona con otros. La actividad es lo que el actor realiza en espaciotiempo. Las etapas se refieren a las fases en que sucede la actividad del actor, y la misión es la finalidad teleológica de la actividad (Páez, 2014).

Según el Diccionario Pequeño Larousse Ilustrado (1974), la formación es la acción de formar o formarse. Aparece como sinónimo de educación e instrucción. Por ello, en materia educativa, a decir de Luz y Caballero (1952), es dar carrera para vivir. "Es el proceso y el resultado cuya función es la de preparar al hombre en todos los aspectos de su personalidad" (Álvarez, 1999, p. 7).

En la Educación Superior cubana, el término formación se emplea para caracterizar el proceso sustantivo desarrollado en las universidades con el objetivo de preparar integralmente al estudiante en una determinada carrera universitaria y abarca, tanto los estudios de pregrado como los de postgrado (Horruitinier, 2007, p.13).

La formación, a partir de las definiciones anteriores, aparece como un proceso multidireccional mediante el cual se transmiten y reciben conocimientos, habilidades, valores, actitudes, costumbres y formas de actuar. Podemos dilucidar y asumimos que se trata de un proceso orientado a preparar integralmente al ser humano para la vida social. Se coincide con Álvarez (1999) en que el proceso de formación es aquel proceso 
en el cual el hombre adquiere su plenitud, tanto desde el punto de vista educativo como instructivo y desarrollador. "Es el proceso totalizador cuyo objetivo es preparar al hombre como ser social” (Álvarez de Zayas, 1999, p. 9).

Para algunos autores (Álvarez \& Fuentes, 2003), el proceso de formación del profesional se concibe como un proceso consciente, holístico, dialéctico y complejo, que se configura en un espacio-tiempo flexible a través de la construcción de significados y sentidos entre sujetos; continuo y social, apoyado por las Tecnologías de la Información y las Comunicaciones, que se desarrolla en las universidades con el propósito de garantizar la formación integral de los profesionales para la adaptabilidad al cambio continuo, mediante la apropiación significativa de la cultura general y profesional.

Por tanto, el proceso de formación del profesional del Derecho en Cuba es actualmente un tema recurrente que adquiere dimensiones ilimitadas a nivel global y también local, tanto en los marcos intra como extra universitarios. El Estado cubano está avocado a desarrollar una cultura política y jurídica en todos sus ciudadanos, con énfasis en los jóvenes, en particular respecto a los temas vinculados al Derecho, al género y la equidad.

En la carrera de Derecho de la universidad cubana, de acuerdo al Plan de estudios vigente, las cuestiones relativas al Derecho Penal se estudian desde la Disciplina: Ciencias Penales, y los delitos contra el normal desarrollo de las relaciones sexuales, se imparten en la asignatura Derecho Penal Especial.

Esta asignatura pertenece a la disciplina Ciencias Penales, se imparte en el tercer año de la carrera y contribuye al desarrollo del perfil profesional propio del jurista, toda vez que proporciona los conocimientos específicos y las referencias jurídicas que permiten a los profesionales del Derecho percibir la dimensión punitiva de determinadas conductas sociales,

El conocimiento de esta materia constituye un referente insoslayable en la preparación del jurista, sobre todo por las altísimas cifras de radicación delictiva de la realidad cubana actual. A través del estudio del Derecho Penal Especial se dota al estudiante de las herramientas jurídicas necesarias para analizar correctamente las normas, instituciones y doctrinas del Derecho Penal, lo cual les permite, desde una concepción dialéctico materialista, calificar acertadamente conductas delictivas, desarrollar convicciones acertadas acerca de la interpretación de las instituciones y normas jurídico-penales, comparar unas figuras delictivas con otras e incluso formular conclusiones provisionales previas al juicio oral.

\section{Consideraciones teóricas sobre género y equidad}

"El género, como concepto, es de reciente incorporación al análisis científico" (Vasallo, 2004, p. 91). La categoría empezó a ser utilizada en las Ciencias Sociales en la década de los setenta en los países del primer mundo (Estados Unidos y Europa), extendiéndose más tarde a América Latina y el Caribe, África y Asia; pero se reconoce su origen en la obra del sicólogo de Nueva Zelandia, Jhon Money, quien en 1951, usa el concepto gender por primera vez para referirse a un componente cultural, 
fundamentalmente a la influencia educativa, en la formación de la identidad sexual (Pautassi, 2012).

En el idioma español, según Lamas (2014), la definición clásica de diccionario, se refiere al género como la clase, especie o tipo a la que pertenecen las personas o las cosas. Plantea que el Diccionario del uso del español, de María Moliner consigna cinco acepciones de género y apenas la última es la relativa al género gramatical, o sea, a la definición gramatical por la cual los sustantivos, adjetivos, artículos o pronombres pueden ser femeninos, masculinos o -sólo los artículos y pronombres- neutros.

Refiere la mencionada investigadora, que según María Moliner, tal división responde a la naturaleza de las cosas sólo cuando esas palabras se aplican a animales, pero a los demás se les asigna género masculino o femenino de manera arbitraria. Concluye planteando que:

En castellano la connotación de género como cuestión relativa a la construcción de lo masculino y lo femenino sólo se comprende en función del género gramatical, y sólo las personas que ya están en antecedentes del debate teórico al respecto lo comprenden como la simbolización o construcción cultural que alude a la relación entre los sexos (Lamas, 2014, p. 2).

Para Lamas, la primera disciplina que empleó la categoría género para establecer una diferencia con el sexo fue la Psicología, en su vertiente médica, por Robert Stoller (Sex and Gender, 1968) quien estudió los trastornos de la identidad sexual, examinando casos en los que la asignación de sexo falló, ya que las características externas de los genitales se prestaban a confusión. Según Izquierdo (1998) tanto para Stoller como para Money se evidenciaban dos cuestiones fundamentales:

- Algunos individuos no podían ser clasificados en machos o hembras desde el punto de vista del dimorfismo sexual porque poseían los caracteres sexuales secundarios poco marcados.

- Otras personas que morfológicamente se encontraban bien definidas sexualmente, declaraban sentirse en un cuerpo equivocado.

Desde esta perspectiva psicológica, para Lamas, el género es una categoría en la que se articulan tres instancias básicas:

$\checkmark$ La asignación (rotulación, atribución) de género, que se realiza en el momento en que nace el bebé, a partir de la apariencia externa de sus genitales.

$\checkmark$ La identidad de género, que se establece más o menos a la misma edad en que el infante adquiere el lenguaje (entre los dos y tres años) y es anterior a su conocimiento de la diferencia anatómica entre los sexos. Desde dicha identidad, el niño estructura su experiencia vital; el género al que pertenece lo hace identificarse en todas sus manifestaciones: sentimientos o actitudes de "niño" o de "niña", comportamientos, juegos, etcétera.

$\checkmark$ El papel de género, que se forma con el conjunto de normas y prescripciones que dictan la sociedad y la cultura sobre el comportamiento femenino o mascu- 
lino. Se puede sostener una división básica que corresponde a la división sexual del trabajo más primitiva: las mujeres paren a los hijos, y por lo tanto, los cuidan: ergo, lo femenino es lo maternal, lo doméstico, contrapuesto con lo masculino como lo público.

Lo que el concepto de género ayuda a comprender es que muchas de las cuestiones que se piensan que son atributos "naturales" de los hombres o de las mujeres, en realidad son características construidas socialmente, que no tienen relación con la biología. El trato diferencial que reciben niños y niñas, sólo por pertenecer a un sexo, va generando una serie de características y conductas diferenciadas (Lamas, 2014, p.4).

Dicha definición se relaciona con el criterio de Lagarde (1994), que concibe también al género como el conjunto de características -asignadas a cada sexo diferencialmente-, y de normas sociales, económicas, políticas, culturales, psicológicas, jurídicas.

Tanto Scott (1990) y Lagarde (1994), como Fleitas (2000), Miranda \& Peña (2001), Fernández (2003), Proveyer (2005) y Caram (2016) coinciden con que el género es una construcción social que se basa en diferencias biológicas.

De acuerdo con la consideración anterior que se vislumbraba desde la década de los años 90, la V Conferencia Internacional de la Mujer celebrada en Beijing, China, en 1995, acordó que la palabra género se diferencia de sexo para expresar que el rol y la condición de hombres y mujeres responden a una construcción social y están sujetos a cambios.

Para Valdebenito (2002), las diferencias entre los hombres y las mujeres son de naturaleza biológica y de carácter social:

El término sexo se refiere a unas diferencias biológicamente determinadas con carácter universal entre los hombres y las mujeres. El término género se refiere a unas diferencias sociales y relacionadas entre los hombres y las mujeres aprendidas, cambiantes con el tiempo y que presentan una gran variabilidad entre las diversas culturas y aun dentro de una misma cultura. Estas diferencias y relaciones son una construcción social, y han sido aprendidas a través del proceso de socialización. Son específicas de un contexto y pueden ser modificadas (p.44).

Por su parte, Vasallo en el 2004, plantea que la formación y desarrollo del género dependen de procesos culturales, del entorno de desarrollo de las personas desde el mismo momento de su nacimiento. Coincidía Caram en 1996, en que es un patrón cultural y diez años después en el 2016 plantea que en cada sociedad tiene su propuesta de modelos para los sexos y que pueden variar a través del tiempo; encontrando su origen en las definiciones sociales y culturales que rigen la conducta de las personas.

Atendiendo a las definiciones anteriores, resulta interesante y a la vez significativo, como desde la década de los años 90 existe consenso en la doctrina, en torno a una definición de género similar y se asume en la investigación al género como un proceso 
de construcción social y/o cultural que asigna a cada persona según su sexo -desde el momento de su nacimiento-, características, roles, valores y normas de todo tipo, ya sean sociales, políticas, económicas, jurídicas, culturales y psicológicas.

Asimismo, se considera que sexo y género no significan lo mismo, en tanto el primero se refiere a las condiciones anátomo-fisiológicas (Miranda \& Peña, 2001; Proveyer, 2005) del ser humano.

El autor considera que, si se entiende al género como una construcción social y también cultural, que parte de la diferencia sexual, esta será el resultado de las luchas acerca de cómo las sociedades definen, entienden y regulan la masculinidad y la feminidad. El debate estará formando parte de dichas luchas, tanto en los espacios privados como en los públicos a través de lo que pudiera denominarse análisis por género.

El análisis por género es una herramienta para diagnosticar las diferencias entre mujeres y hombres. Contempla sus actividades específicas, condiciones, necesidades, su acceso a los recursos y el control que tienen sobre ellos, así como su acceso a los beneficios del desarrollo y a los niveles de dirección. Estudia estos vínculos y otros factores en el medio y en el contexto más amplio social y económico (...) es el primer paso de una planificación sensible a las cuestiones de género para promover la igualdad entre las mujeres y los hombres (...) el primer paso para la formación de cualquier política o elaboración de un programa: el punto de partida desde el que transformar la naturaleza del desarrollo de una sociedad para promover la igualdad entre los hombres y las mujeres (Valdebenito, 2002, p.30).

Dicho análisis por género puede tenerse en cuenta para cualquier estudio que se vaya a desarrollar, ya sea de perspectiva de género o enfoque de género. Este último se concibe según Ahr (2007), como los diferentes papeles que la sociedad asigna a mujeres y hombres y que se reflejan, en la división y carga de trabajo, en el diferente acceso a los recursos y el desigual control sobre ellos, así como en las distintas posibilidades que tienen las personas de ejercer influencia política y social.

Debe considerarse además, que para llevar a cabo el análisis del enfoque de género, la finalidad debe estar siempre dirigida a disminuir o erradicar las brechas de desigualdad, o sea, lograr la justicia y la equidad entre hombres y mujeres.

Para el Derecho romano, justicia es la palabra de donde proviene el ius (Derecho) y se define como el arte de lo bueno y lo equitativo. Para Ulpiano (s/f) era: "la voluntad constante y perpetua de dar a cada uno el derecho que le pertenece" (p.11). Dicha definición de Ulpiano esboza que "la justicia no consistía en un trato igual para todos, sino que por el contrario consistía en dar a cada uno lo que le correspondiera, es decir, afirmaba como justa la desigualdad" (Fernández; Carreras \& Yánez, 2006, p.11).

La equidad como una palabra frecuente en el Derecho romano fue utilizada algunas veces para la promulgación de nuevas leyes, otras para servir de fundamento a normas que dictaban lo pretores y otras para distinguir desde el punto de vista el arbitrio judicial, cuándo es posible que el juzgador decida un pleito por razones de equidad y buena fe (Fernández; Carreras \& Yánez, 2006). 
En relación con ello y sobre esa base, la equidad de genero, plantea Miranda y Peña (2001) "está muy presente en la humanidad, desde los inicios de la vida social, económica, política. Desde aquel entonces la mujer no tenía derecho a ser escuchada, ni a opinar, ni mucho menos a ser parte de una familia y sociedad" (p.77).

Según Valdebenito (2002) supone un disfrute de los bienes sociales, recursos, las mismas oportunidades en la toma de decisiones, y trabajar juntos ambos sexos para lograrlo.

Dicha equidad como se mencionó, no es sinónimo de igualdad con respecto al género. Para la autora anterior, las responsabilidades y las oportunidades de las mujeres y de los hombres no dependan de que hayan nacido mujeres u hombres; es un problema de derechos humanos y una condición previa para la consecución de un desarrollo sostenible centrado en las personas.

Para Miranda \& Peña (2001) equidad de género es la distribución justa de acuerdo a los intereses y necesidades de hombres y mujeres, es tener derecho a acceder con justicia e igualdad al uso, control y beneficio de los mismos bienes y servicios de la sociedad, así como a la toma de decisiones en los ámbitos de la vida social, económica, política, cultural y familiar.

"Es la aceptación de las diferencias entre hombres y mujeres, y la aceptación también de derechos, buscando el ideal de un equilibrio en el que ninguno de ambos sexos se beneficie de manera injusta en prejuicio del otro" (p. 77).

La I Conferencia Mundial sobre la Mujer, en México (1975) que culminó con la propuesta de un Plan de Acción aprobado por la Asamblea de las Naciones Unidas, acordó que la igualdad es al mismo tiempo un objetivo y un medio por el cual los individuos se benefician del mismo trato en el marco de la ley y de las mismas oportunidades para gozar sus derechos y desarrollar sus talentos y habilidades de manera que puedan participar en el desarrollo político, económico, social y cultural, tanto como beneficiarios que como agentes activos.

En tanto Valdebenito (2002) coinciden con la definición anterior al plantear, la "igualdad de derechos significa igualdad formal ante la ley. Equiparación de hombres y mujeres mediante medidas legislativas" (p. 37). Dicha igualdad está establecida o amparada "en principio" por la Constitución de cada país, y como ya se planteó en la introducción del estudio Cuba la regula en el Capítulo VI del artículo 41 al 44.

En cuanto a la "igualdad de género se entiende como una relación de equivalencia en el sentido de que las personas tienen el mismo valor, independientemente de su sexo, y por ello son iguales" (Valdebenito, 2002, p. 37).

Desde el punto de vista del Derecho, según Camargo (1991), la perspectiva de género "establece una teoría social que trata de explicar (...) comportamientos sociales de hombres y mujeres en sociedad, (...) destacando la existencia real del género femenino y masculino, sin dominio de uno sobre el otro, sin jerarquías y sin desigualdades" ( $p$. 29).

Para la abogada Staff (1999), la perspectiva de género, significa la promoción de la igualdad y de las nuevas identidades de género, reduciendo o eliminando las causas y efectos de la discriminación en el ámbito jurídico. 
Según Valdebenito en el 2002, es "tomar en consideración y prestar atención a las diferencias entre mujeres y hombres en cualquier actividad o ámbito dados en una política" (p.41).

El investigador está de acuerdo con Miranda \& Peña (2001) y Valdebenito (2002), en que la equidad de género no supone que hombres y mujeres sean iguales, pero sí que tengan acceso y disfruten de los bienes sociales, oportunidades y recursos sin distinción alguna, sin que un sexo prevalezca por encima del otro.

El énfasis en la igualdad y en el empoderamiento de género, no presupone un modelo definitivo de igualdad para todas las sociedades, pero refleja la preocupación de que ambos sexos, aunque no sean iguales por razones biológicas, sí tengan las mismas facilidades para tomar decisiones y trabajen juntos para lograrlo en virtud del principio de equidad.

A tenor de la investigación se entenderá por enfoque de género en el Derecho Penal cubano desde la perspectiva de la equidad, la posición y el tratamiento que ofrece para hombres y mujeres el conjunto de normas que dan orden estructural y funcional a esta rama del Derecho, sobre la base de un equilibrio en el que ninguno de ambos sexos se beneficie de manera injusta por encima del otro.

\section{El enfoque de género en el Derecho Penal desde la perspectiva de la equidad}

El Derecho Penal es aquella rama del ordenamiento jurídico general caracterizada por el conjunto de normas, conceptos, tesis, juicios, postulados, principios y categorías, relacionadas con la actividad delictiva en una sociedad determinada (Matilla, s/f, p. 265).

Las funciones básicas del Derecho Penal hacen referencia a los modos de influencia de este con respecto a las relaciones sociales, y dicha influencia se lleva a cabo, principalmente, de dos modos. De una parte, confiere particular protección del sistema de relaciones sociales (función de protección); y de otra, procura promover en todas las personas la observancia y desarrollo de comportamientos ajustados, precisamente, a dicho sistema de relaciones sociales (función de motivación).

Una y otra función las realiza el Derecho Penal mediante la definición, en normas jurídicas, de ciertas conductas altamente peligrosas para el mencionado sistema de relaciones sociales y la aplicación de medidas jurídicas (las penas) a aquellos sujetos que incurren en los comportamientos prohibidos.

Conforme se advertirá, aquí se ponen de manifiesto, no solo las dos funciones asignadas al Derecho Penal, sino los vínculos de ésta con las funciones de la norma penal y con las funciones de la sanción penal. El artículo 1.1 del Código Penal recoge estas funciones, en el cual el primer objetivo es la función de protección y los dos restantes la función de motivación.

Dentro del Derecho Penal, según Goite (2003) el Derecho Penal Especial constituye una unidad lógica de conocimientos teórico-prácticos de la parte especial del Código Penal, que tiene como precedentes el Derecho Penal General. 
La norma sustantiva cubana, en el caso del Código Penal o Ley No. 62 de 29 de diciembre de 1987, puesto en vigor el 30 de abril de 1988 y modificado por el DecretoLey No. 150 de junio de 1994, con sus dos últimas modificaciones: el Decreto-Ley 175, de 17 de junio de 1997 y la Ley 87 de 16 de febrero de 1999, regula en el capítulo XI los delitos contra el normal desarrollo de las relaciones sexuales.

Los tipos penales de Violación, Pederastia con Violencia y Abusos lascivos, tienen, en sus figuras básicas, la siguiente regulación jurídico-penal:

Artículo 298.1: Se sanciona con privación de libertad de cuatro a diez años al que tenga acceso carnal con una mujer sea por vía normal o contra natura, siempre que en el hecho concurra alguna de las circunstancias siguientes:

a) usar el culpable de fuerza o intimidación suficiente para conseguir su propósito;

b) hallarse la víctima en estado de enajenación mental...o carente de la facultad de dirigir su conducta.

Artículo 299.1: El que cometa actos de pederastia activa empleando violencia o intimidación, o aprovechando que la víctima esté privada de razón o de sentido o incapacitada para resistir, es sancionado con privación de libertad de siete a quince años.

Artículo 300.1: El que, sin ánimo de acceso carnal, abuse lascivamente de una persona de uno u otro sexo, concurriendo cualquiera de las circunstancias previstas en el apartado 1 del artículo 298, incurre en sanción de privación de libertad de seis meses a dos años o multa de doscientas a quinientas cuotas.

Con la regulación de dichos delitos en el Código Penal vigente desde 1987 según Rega (2003), se incorporan actos, agresiones y abusos sexuales que atentan directa o indirectamente contra el normal desenvolvimiento de las relaciones sexuales.

Estas figuras delictivas incluyen tanto la libertad del sujeto de elegir de forma autónoma en el ámbito de la sexualidad lo referente a la excitación y satisfacción sin traspasar las barreras del Derecho Penal, así como de elegir su pareja, determinar la opción sexual que se prefiera en cada momento.

El enfoque de género a partir de un análisis crítico en ambos delitos y desde la perspectiva de equidad, atendiendo a los sujetos que intervienen y el marco sancionador, permite apreciar que el legislador cubano formuló dos figuras de delitos analógicamente semejantes por presentar conductas similares, pero con diferencias punitivas para ambos sexos.

En el caso de la Violación, según la previsión legislativa del artículo, se presenta solo a la mujer como sujeto pasivo del delito, mientras que en la Pederastia con Violencia la acción recae sobre el hombre.

En el caso de la sanción, se evidencia en el marco sancionador del delito de Violación de cuatro a diez años, a la mujer, con un tratamiento desventajoso con respecto al marco sancionador del hombre en la Pederastia con Violencia, lo que evidencia o sugiere que el legislador otorgó con la plasmación de tal diferenciación, una mayor protección a la integridad sexual del hombre de siete a quince años, como si fuera de superior valor a la integridad sexual de la mujer de cuatro a diez años. 
Según la consideración del autor, se está en presencia de una concepción expresada en Ley, de carácter tradicionalista y sexista, que no otorga el mismo tratamiento para ambos sexos, aún cuando la propia práctica jurídica y social indica que la Violación tiene mayor incidencia que la Pederastia con Violencia.

Al decir de Rega (2003) "el término Violación sin dudas de gran tradición cultural, criminológica y legal, no ha logrado romper la idea que la asocia con la relación heterosexual, donde solo puede ser sujeto pasivo la mujer" (p.137).

Se está en definitiva, en presencia de disposiciones normativas que suponen una diferencia de género por ende discriminatoria, que reconoce que en materia penal en Cuba, no se ha logrado superar el tratamiento del contexto del delito de Violación, con cualquier persona, dígase hombre o mujer como sujeto pasivo del delito.

Es preciso aclarar -partiendo del análisis del enfoque de género-, que no ocurre lo mismo en el delito de Abusos Lascivos, donde sí se contemplan como sujetos pasivos a ambos sexos, concurriendo inclusive cualquiera de las circunstancias previstas en el apartado 1 del artículo 298 Violación, lo que presupone y ratifica la concepción tradicionalista predominante en el modo de pensamiento del legislador cubano al plasmar las figuras delictivas de la Violación y la Pederastia con Violencia.

Se considera que dicha problemática hubiera sido resuelta con una única norma que contemplara a ambos sexos como sujetos pasivos de los dos delitos antes mencionados y como se evidencia en materia penal en países del Sistema de Derecho Romano-Francés como Venezuela, Argentina, España y Bolivia.

\section{Comparación jurídica a la regulación del delito de Violación}

En materia de Derecho Comparado, en la actualidad, según Silva \& Pérez (2017), una mirada al enfoque de género desde la perspectiva de la equidad, demuestra que, a pesar de que la política social y jurídica está encaminada a que no haya diferencias entre ambos sexos, existen normas tendentes a favorecer al hombre y a discriminar a la mujer, violando de esta manera lo establecido por la Asamblea General de las Naciones Unidas que adoptó en el año 1999 el Protocolo Facultativo a la Convención sobre la "Eliminación de todas las formas de discriminación contra la mujer", firmado por más de 70 Estados y ratificado por 100.

El delito de Violación en materia penal, sugiere revisar el tratamiento dado por el Código Penal de los siguientes países: España, porque es el tronco del cual emanó todo el ordenamiento jurídico latinoamericano; Venezuela y Bolivia porque son de los casos cuyo enfoque sociopolítico es más semejante al cubano, y Argentina, Costa Rica, Italia, Alemania y Colombia porque son de los países que se reconocen como de mayor desarrollo de su ordenamiento jurídico y su actividad jurisprudencial.

El Código Penal de Venezuela, divulgado por la Gaceta Oficial № 5.494 Extraordinario del 20 de octubre de 2000, plantea en su Título VIII, Capítulo I "De la violación, de la seducción, de la prostitución o corrupción de menores y de los ultrajes al pudor":

Artículo 375.- "El que por medio de violencias o amenazas haya constreñido a alguna persona, del uno o del otro sexo, a un acto carnal, será castigado con presidio de cinco a diez años". 
Por su parte, el Código Penal de Argentina actualizado o Ley 11.179 de 1984, en su Capítulo II, Artículo 119 plantea: "Será reprimido con reclusión o prisión de seis meses a cuatro años el que abusare sexualmente de persona de uno u otro sexo cuando, ésta fuera menor de trece años o cuando mediare violencia, amenaza, abuso coactivo o intimidatorio de una relación de dependencia, de autoridad, o de poder, o aprovechándose de que la víctima por cualquier causa no haya podido consentir libremente la acción".

El Código Penal de España (Ley Orgánica 10/1995, de 23 de noviembre) en su Capítulo I: De las agresiones sexuales, pertenecientes al TíTULO VIII Delitos contra la libertad e indemnidad sexuales, en el Artículo 178 regula que: "El que atentare contra la libertad sexual de otra persona, utilizando violencia o intimidación, será castigado como responsable de agresión sexual con la pena de prisión de uno a cinco años".

En Bolivia, el Código Penal, modificado por la Ley 2033 de 1999 en su artículo 308 establece: "Quien empleando violencia física o intimidación, tuviera acceso carnal con persona de uno u otro sexo; penetración anal o vaginal o introdujera objetos con fines libidinosos (...)".

En el caso de Alemania, el Código Penal del 15 de mayo de 1871, con la última reforma del 31 de enero de 1998, plantea en su Sección Decimotercera: Hechos punibles contra la autodeterminación sexual, que:

Artículo 177. Acceso carnal violento; violación

(1) Quien coacciona a una persona con violencia, por medio de amenaza con peligro inminente para el cuerpo la vida, o bajo aprovechamiento de una situación en la que la víctima es entregada sin protección a la actuación del autor, a tolerar sobre si acciones sexuales del autor o de un tercero o las practique en el autor o en un tercero, será castigado con pena privativa de la libertad no inferior a un año.

Artículo 178. Acceso carnal violento y violación con resultado de muerte

Si el autor a través de la violencia sexual o de la violación (177) causa como mínimo por imprudencia la muerte de la víctima, entonces el castigo es de pena privativa de la libertad perpetúa o pena privativa de la libertad no inferior a diez años.

El Código Penal de Costa Rica, Ley No. 4573 publicado en la GACETA No. 257 DE 15-111970en el Título III: Delitos sexuales en su Sección I. Violación, estupro, y abuso deshonesto regula en el Artículo 156.- Será sancionado con pena de prisión de diez a dieciséis años, quien se haga acceder o tenga acceso carnal, por vía oral, anal o vaginal, con una persona de cualquier sexo, en los siguientes casos:

1) Cuando la víctima sea menor de doce años.

2) Cuando la víctima sea incapaz o se encuentre incapacitada para resistir.

3) Cuando se emplee la violencia corporal o intimidación. La misma pena se impondrá si la acción consiste en introducir, por vía vaginal o anal uno o varios dedos u objetos.

El Código Penal Ecuador, en el Título VIII: De los delitos sexuales en el Capítulo II. Del atentado contra el pudor, de la violación y del estupro plantea en el Artículo. 512.-

Violación es el acceso carnal, con introducción parcial o total del miembro viril, por vía vaginal, anal o bucal, con personas de uno u otro sexo, en los siguientes casos: 
1. Cuando la víctima fuere menor de catorce años;

2. Cuando la persona ofendida se hallare privada de la razón o del sentido, o cuando por enfermedad o por cualquier otra causa no pudiera resistirse; $y$,

3. Cuando se usare de violencia, amenaza o de intimidación.

El Código Penal de Italia en el Título IX: Delitos contra la moral pública y las buenas costumbres, en el Capítulo I: Delitos contra la libertad sexual, en su Artículo 519 de la Violencia carnal, plantea que "El que, mediante violencia o amenazas, obligue a otra persona a tener relaciones sexuales será castigado con prisión de tres a diez años.

Por último el Código Penal de Colombia en el Título IV. Delitos contra la libertad, integridad y formación sexuales, en el Capítulo Primero De la violación refiere en el Artículo 205 - Acceso carnal violento. El que realice acceso carnal con otra persona mediante violencia, incurrirá en prisión de ocho (8) a quince (15) años.

Artículo 206 - Acto sexual violento.- El que realice en otra persona acto sexual diverso al acceso carnal mediante violencia, incurrirá en prisión de tres (3) a seis (6) años.

Al analizar cada uno de los casos citados anteriormente, se llega a la conclusión de que existen diferencias entre las figuras delictivas de la violación de los países expuestos y la norma cubana que contempla dicho delito en el Código Penal.

La diferencia más significativa radica en los sujetos pasivos en los que recae la violación, pues tanto España como Venezuela, Colombia, Ecuador, Italia, Bolivia, Argentina, Costa Rica y Alemania, lo regulan en una misma normativa para ambos sexos sin necesidad de establecer la misma conducta o esencia delictiva con marcos sancionadores diferentes para el hombre o la mujer, otorgándole a ambos el mismo valor e importancia.

Tales regulaciones, constituyen modelos de países cuyo Código Penal ha tenido en cuenta la equidad de género en la regulación del delito de Violación, un patrón a seguir por quienes legislan en Cuba, que tienen la responsabilidad de crear disposiciones normativas cada vez más equitativas en materia penal.

\section{CONSIDERACIONES FINALES}

La formación de profesionales universitarios en Cuba, orientada por el Ministerio de Educación Superior a preparar integralmente al ser humano para la vida social, necesita incorporar en el proceso de enseñanza-aprendizaje del Derecho Penal en la carrera de Derecho, al enfoque de género desde la perspectiva de la equidad.

Dicha enseñanza del Derecho Penal con un enfoque de género que responda a la perspectiva de la equidad en los delitos contra el normal desarrollo de las relaciones sexuales regulados en el Código Penal, en la carrera de Derecho, reviste especial importancia para la formación del profesional, en la medida en que trasciende a la justicia social por el posterior tratamiento de dichos delitos en la práctica laboral como operadores del Derecho.

A partir del análisis crítico de la Violación y la Pederastia con violencia se obtuvo, que el enfoque de género de estas disposiciones es de carácter tradicionalista y sexista, atendiendo a los sujetos que intervienen y el marco sancionador, pues el legislador 
cubano formuló dos figuras de delitos analógicamente semejantes por presentar conductas similares, pero con diferencias punitivas en el marco sancionador para ambos sexos, ofreciéndose mayor importancia a la integridad sexual del hombre (de 7 a 15 años) que a la de la mujer (de 4 a 10 años).

No ocurre lo mismo en el delito de Abusos Lascivos donde se contemplan a ambos sexos como sujetos pasivos y se establece igual marco sancionador, presentando un enfoque de género que se ajusta a la perspectiva de la equidad.

La adecuada regulación del delito de Violación en países como Venezuela, Costa Rica, Argentina, Colombia, España, Ecuador, Alemania, Italia y Bolivia constituye un modelo a seguir por Cuba en función de la equidad de género que necesita la Ley cubana, en tanto su normativa establece la misma conducta delictiva con igual marco sancionador para el hombre y la mujer, lo que le otorga a la integridad sexual de ambos sexos el mismo valor e importancia.

Se considera que debe aprobarse y ponerse en práctica en Cuba por quienes legislan, un Decreto-Ley con carácter modificativo para derogar los delitos de Violación y Pederastia con violencia, establecidos en el vigente Código Penal. Dicho Decreto-Ley pudiera concebir la regulación de los delitos anteriores en una misma figura delictiva de la siguiente forma:

Se sanciona con privación de libertad de cuatro a diez años al que tenga acceso carnal con una persona de uno u otro sexo, siempre que en el hecho concurra alguna de las circunstancias siguientes:

a) usar el culpable de fuerza o intimidación suficiente para conseguir su propósito;

b) hallarse la víctima en estado de enajenación mental...o carente de la facultad de dirigir su conducta.

El estudio presentado, en sentido general, evidencia que la Universidad cubana se encuentra expuesta a retos que presuponen la inserción de los estudios de equidad de género en la enseñanza del Derecho, en aras de perfeccionar la formación de juristas con una proyección axiológica tendente a disminuir los sesgos discriminatorios en la impartición de justicia. 


\section{REFERENCIAS BIBLIOGRÁFICAS}

- Alemania. Código Penal (1871, 15 de mayo), con la última reforma del 31 de enero de 1998. Citado 17 jul 2017. Disponible en:

https://www.unifr.ch/ddp1/derechopenal/obrasjuridicas/oj_20080609_13.pdf

- Álvarez de Zayas, C. (1999). Didáctica: la escuela en la vida. 3ra edición corregida y aumentada. La Habana: Editorial Pueblo y Educación.

- Álvarez, I. B \& Fuentes, H. C. (2003). Didáctica del proceso de formación de los profesionales asistido por las Tecnologías de la Información y la Comunicación. Santiago de Cuba: Manuscrito no publicado.

- Ahr, I, (2007). Género y Educación. Cuaderno temático. Perú: Ed. EBRA E.I.R.L.

- Argentina. Código Penal. Ley 11.179 de 1984 (Actualizado). Citado 17 jul 2017. Disponible en: http://servicios.infoleg.gob.ar/infoleg/nternet/anexos/1500019999/16546/texact.htm

- Bolivia. Código Penal, Ley no 1768 modificado por la Ley 2033/ 1999. Citado 15 jul 2017. Disponible en:

http://www2.congreso.gob.pe/sicr/cendocbib/con4 uibd.nsf/46CA85EA04EBEE40052 57D2C007035D4/SFILE/CODIGOPENALDEBOLIVIA.pdf

- Camargo, J. (1999). Género e Investigación Social. Curso de Formación en Género. Módulo 2. Instituto de la Mujer de la Universidad de Panamá/ UNICEF. Editora Sibauste, Primera edición.

- Caram, T. (1996). La Mujer cubana y la participación social: educación y ciencia. Tesis de Maestría, Programa FLACSO Cuba, Universidad de La Habana.

- Caram, T. (2016). Oportunidades y posibilidades para el empoderamiento. Revista Estudios del Desarrollo Social: Cuba y América Latina, 4 (4), Número Extraordinario, 176-189. Disponible en: http://ojs.uh.cu/DesarrolloSocial/index.php/EDS

- Colectivo de Autores. (1984). Pedagogía. La Habana: Editorial Pueblo y Educación.

- Colombia. Código Penal, Ley 599 de 24 de julio de 2000. Citado 17 jul 2017. Disponible en: http://www.alcaldiabogota.gov.co/sisjur/normas/Norma1.jsp?i=6388

- Costa Rica. Código Penal, Ley № 4573 y sus reformas del 4 de marzo de 1970. Citado 17 jul 2017. Disponible en: $\underline{\text { https://www.poder- }}$ judicial.go.cr/penaljuvenil/index.php/legislacion

- Cuba. Código Penal. Ley No. 62, (29 de diciembre de 1987) Actualizado. Colección Jurídica. Ministerio de Justicia. La Habana, 1999.

- Cuba. Constitución de la República (actualizada). Revisada y concordada por la Dirección de Legislación y Asesoría del Ministerio de Justicia. La Habana, 2005.

- De la Luz y Caballero, J. (1952). Elencos y discursos académicos. La Habana: Editorial de la Universidad de La Habana. 
- Diccionario Pequeño Larousse Ilustrado (1974). Palabra proceso. La Habana: Pueblo y Educación.

- Ecuador. Código Penal, Decreto Supremo No. 55, de 8 de julio de 1970, publicado por el Registro Oficial, Suplemento 147 de 22 de Enero de 1971. Citado 13 jul 2017. Disponible en: https://www.oas.org/juridico/mla/sp/ecu/sp ecu-int-text-cp.pdf

- España. Código Penal. Ley Orgánica 10 (1995, 23 de noviembre). BOE no. 281/24 de noviembre de 1995. España: Editorial QUILES. Disponible en:

https://vlex.es/tags/codigo-penal-españa-730039

- Fernández, J., Carreras, D. \& Yánez, R.M. (2006). Manual de Derecho Romano. La Habana: Editorial Félix Varela.

- Fernández, L. (2003). Género y subjetividad. En Fernández, L. Pensar en la Personalidad. La Habana: Editorial Félix Varela.

- Fleitas, R. (2000): "Identidad femenina y maternidad adolescente", Tesis de doctorado, Departamento de Sociología, Universidad de La Habana, Cuba.

- Goite, M. (2003): Derecho Penal Especial, tomo II. La Habana: Ed. Félix Varela.

- Horruitiner, P. (2007). La Universidad cubana: el modelo de formación. Capítulo II.

El proceso de formación. Sus características. Pedagogía Universitaria, Vol. XII, No. 4.

- Italia. Código Penal (aprobado por Decreto Real № 1398 de 19 de octubre de 1930), con las modificaciones de la Ley $N^{\circ} 547$, de 23 de diciembre de 1993. Citado 15 jul 2017.Disponible en:

http://perso.unifr.ch/derechopenal/assets/files/legislacion/l 20080616 59.pdf

- Izquierdo, M. J. (1998). El malestar en la desigualdad. España: Ed. Cátedra de la Universidad de Valencia. Disponible en:

https://www.researchgate.net/publication/39081633 IZQUIERDO Maria Jesus EI ma lestar en la desigualdad

- Lagarde, M. (1994). La regulación social de género: el género filtro de poder. México. Consejo Nacional de Población.

- Lamas, M. (2014). La perspectiva de género. Recuperado de:

http://www.latarea.com.mx/articu8/lamas8.htm

- Matilla, A. (s/f). Introducción al Derecho. Holguín: Centro Gráfico de Reproducciones para el Turismo.

- Miranda, B. \& Peña, V. (2001). Relaciones de Genero con Equidad: Guía conceptual

y metodológica. Holanda: Editorial IICA-Holanda. Disponible en:

http://repiica.iica.int/docs/B1178e/B1178e.pdf

- Páez, L. (2014). Modelo de formación de estudiantes de derecho para la litigación. Una estrategia para su implementación en la Universidad de Pinar del Río. Tesis de Maestría no publicada, Universidad "Hermanos Saíz Montes de Oca", Pinar del Río, Cuba.

- Pautassi, L. (2012). "La igualdad en espera: el enfoque de género". Lecciones y Ensayos, nro. 89.

- Proveyer, C. (2005). Selección de lecturas de Sociología y Política Social de Género. La Habana: Editorial Félix Varela, 2005: 1. En Gomáriz, Enrique. Los estudios de género 
y sus fuentes epistemológicas: periodización y perspectivas. Chile. Editorial FLACSO, 1922.

- Rega, E. (2003): Derecho Penal Especial, tomo II. La Habana: Ed. Félix Varela.

- Rosental, M. y Ludin, P. (1981). Diccionario Filosófico. La Habana: Editora Política.

- Scott, J. (1990). El género: una categoría útil para el análisis histórico. Recuperado de http://www.cholonautas.edu.pe/modulo/upload/scott.pdf

- Silva, J. L., Páez, L. D., \& Simón, A. (2016). La relación entre Derecho Internacional Público -Seguridad Nacional para el estudiante de Derecho en Cuba. Universidad y Sociedad [seriada en línea], 8 (4), pp. 149-155. Recuperado de http://rus.ucf.edu.cu

- Silva, J. L. \& Pérez, A. (2017). El enfoque de género en la evolución del ordenamiento jurídico cubano y su manifestación en el Derecho Penal actual. Revista Estudios del Desarrollo Social: Cuba y América Latina. Vol. 5, No. 2, 1-11.

http://ojs.uh.cu/DesarrolloSocial/index.php/EDS

- Staff, M, (2000). Género y Derecho. Curso de Formación en Género. Módulo 3. Instituto de la Mujer de la Universidad de Panamá. Editora Sibauste, Primera edición. Legalinfo, Panamá.http://www.legalinfo-panama.com/articulos/articulos 21f.htm

- Stoller R (1994). Sex and Gender: On the Development of Masculinity and Femininity, Science House. New York City. 383 Disponible en:

http://us.karnacbooks.com/product/sex-and-gender-the-development-of-masculinityand-femininity/22/

- Valdebenito, E. (2002). "Género y Desarrollo (algunas reflexiones y un glosario práctico para facilitar el trabajo a nivel local)". Programa DelNet - Gender Equality Centro Internacional de Formación de la OIT. Recuperado de: http://www.itcilo.it/delnet

- Vasallo, N. (2004). El género: un análisis de la "naturalización" de las desigualdades. En Colectivo de autores. Heterogeneidad social en la Cuba actual Centros de Estudio y Bienestar Humano. Universidad de La Habana, Cuba.

- Venezuela. Código Penal (2000, 20 de octubre). Gaceta Oficial de la República Bolivariana de Venezuela № 5.494 (Extraordinario) 2000. Citado 8 dic 2016. Disponible en: http://www.oas.org/juridico/spanish/mesicic3 ven anexo6.pdf 